Research Paper

\title{
A Prospective Randomized Experimental Study to Investigate the Eradication Rate of Endometriosis after Surgical Resection versus Aerosol Plasma Coagulation in a Rat Model
}

\author{
Ralf Rothmund ${ }^{1}$, Marcus Scharpf ${ }^{2}$, Christos Tsaousidis ${ }^{1}$, Constanze Planck1, Markus Dominik Enderle ${ }^{3}$, \\ Alexander Neugebauer ${ }^{3}$, Kristin Kroeker ${ }^{3}$, Daniela Nuessle ${ }^{3}$, Falko Fend ${ }^{2}$, Sara Brucker ${ }^{1}$, Bernhard \\ Kraemer $^{1}$ \\ 1. Department of Obstetrics and Gynaecology, University of Tuebingen, Calwerstr. 7, 72076 Tuebingen, Germany (Director: Prof. D. Wallwiener); \\ 2. Department of Pathology, University of Tuebingen, Liebermeisterstr. 8, 72076 Tuebingen, Germany (Director: Prof. F. Fend); \\ 3. Erbe Elektromedizin GmbH, Waldhoernlestr. 17, 72072 Tuebingen, Germany. \\ $\triangle$ Corresponding author: PD Dr. med. Bernhard Kraemer, Department of Obstetrics and Gynaecology, University of Tuebingen, Calwerstr. 7,72076 Tuebingen. \\ Tel.: +49-7071/29-86340 E-Mail: Bernhard.Kraemer@med.uni-tuebingen.de.
}

(C) Ivyspring International Publisher. Reproduction is permitted for personal, noncommercial use, provided that the article is in whole, unmodified, and properly cited. See http://ivyspring.com/terms for terms and conditions.

Received: 2015.12.20; Accepted: 2016.01.22; Published: 2016.02.18

\begin{abstract}
Purpose To investigate the eradication rate of endometriosis after surgical resection (SR) vs. thermal ablation with aerosol plasma coagulation (AePC) in a rat model.

Methods In this prospective, randomized, controlled, single-blinded animal study endometriosis was induced on the abdominal wall of 34 female Wistar rats. After 14 days endometriosis was either removed by SR or ablated by AePC. 14 days later the rats were euthanized to evaluate the eradication rate histopathologically. Intervention times were recorded.

Results Eradication rate of endometriosis after 14 days did not significantly differ between AePC and SR $(p=0.22)$. Intervention time per endometrial lesion was $22.1 \mathrm{~s}$ for AePC and $51.8 \mathrm{~s}$ for SR $(p<0.0001)$.

Conclusions This study compares the eradication rate of the new aerosol plasma coagulation device versus standard surgical resection of endometriosis in a rat model. Despite being a thermal method, AePC showed equality towards SR regarding eradication rate but with significantly shorter intervention time.
\end{abstract}

Key words: aerosol plasma coagulation, endometriosis, rat model, non-contact method, thermal damage.

\section{Introduction}

Endometriosis is a benign but painful gynaecological disease which affects $10-15 \%$ of women of reproductive age [1]. Surgical removal of endometrial lesions by laparoscopic excision is considered as the gold standard in endometriosis therapy [2].

Common complications after surgical removal of endometrial tissue from the pelvis result from adhesion formation due to peritoneal traumatization by mechanical contact or thermal damage of the highly sensitive peritoneum.

Several techniques are available for endometrio- sis treatment, such as thermal coagulation, vaporization and excision; however their equivalence is not yet clarified. Advantages of argon plasma coagulation within endometriosis ablation regarding fertility have already been presented [3].

Aerosol plasma coagulation (AePC) is a new variation of the well-known argon plasma coagulation (APC) method which combines the argon plasma for coagulation with a stream of fine water droplets (water jet technology) to produce a more homogenous tissue effect with less carbonization, less inflammation 
as well as the emission of surgical smoke to a minimum level in one device. This laminar flow of nebulized water reduces the issue of APC induced dessication and adhesions depending on the energy intake. AePC shows a significantly lower rate of adhesion formation compared to standard APC mainly due to improved peritoneal conditioning [4] and lower temperature on the tissue surface.

The aim of this experimental animal study is to compare the eradication rate of endometriosis after aerosol plasma coagulation with surgical resection in a rodent model.

\section{Material and Methods}

\section{Study design}

This prospective, randomized, controlled, and single-blinded study was approved by the Institutional Review Board (Ethics Committee of the Regional Board in Tuebingen, Germany, registration number F 1-13). The primary objective of the study was the eradication rate of endometriosis after aerosol plasma coagulation compared to surgical resection. Secondary objectives were the duration of intervention and histological findings. The number of animals used to assess the non-inferiority in eradication rate using aerosol plasma coagulation compared to surgical resection was prospectively calculated by the Department of Medical Biometry (University of Tuebingen, Tuebingen, Germany). Randomization was done by assigning each peritoneal side of a rat to one of the two possible treatment methods by a computer-generated randomization list.

\section{Animals}

Female Wistar rats ( $\mathrm{n}=34$ animals) (Charles River Laboratories, Sulzfeld, Germany) with an average weight of $282 \pm 19 \mathrm{~g}$ were housed under laboratory conditions (temperature: mean $21^{\circ} \mathrm{C} \pm 2{ }^{\circ} \mathrm{C}$ standard deviation, humidity: mean 55\% $\pm 10 \%$ standard deviation, 12:12-hour light-dark-cycle) for ten days. Food (10 mm pellets, Provimi Kliba AG, Kaiseraugst, Switzerland) and tap water were available ad libitum. Pre-operatively, a maximum of four animals were kept per cage (1354G Eurostandard type IV cages, Tecniplast Deutschland $\mathrm{GmbH}$, Hohenpeissenberg, Germany) in no particular order. Cages were lined with $5 \times 5 \times 1 \mathrm{~mm}$ wood chips (Abedd Lab \& Vet Service $\mathrm{GmbH}$, Vienna, Austria). After each surgical procedure the animals were housed in separate cages $(1291 \mathrm{H}$ Eurostandard type III H cages, Tecniplast Deutschland $\mathrm{GmbH}$, Hohenpeissenberg, Germany), each lined with unbleached chemical pulp (Paul Hartmann AG, Heidenheim, Germany). After post-operative day 2, four animals were kept per cage (1354G Eurostandard type IV cages, Tecniplast
Deutschland $\mathrm{GmbH}$, Hohenpeissenberg, Germany). These cages were lined with $5 \times 5 \times 1 \mathrm{~mm}$ wood chips (Abedd - lab \& vet Service GmbH, Vienna, Austria).

\section{Pre-operative hormone treatment}

All rats were given estradiol $(50 \mu \mathrm{g} / \mathrm{kg})$ s.c twice a week before endometriosis induction for hormonal synchronization.

\section{First surgery: induction of endometriosis}

The surgical procedure was performed under aseptic conditions in a dedicated microsurgical animal operating theatre located at the Department of Obstetrics and Gynaecology, University of Tuebingen. Anaesthesia was induced using inhaled isoflurane (Abbott, Wiesbaden, Germany) with the animals breathing spontaneously. Analgesia was provided using a pre-operative subcutaneous injection of buprenorphine $(0.05 \mathrm{mg} / \mathrm{kg})$. The animals were placed on a heating mat warmed to $38{ }^{\circ} \mathrm{C}$ (ThermoLux Waermeunterlage, Witte + Sutor $\mathrm{GmbH}$, Murrhardt, Germany). After shaving with electrical clippers (Favorita II, Aesculap AG, Tuttlingen, Germany), the surgical field was disinfected (Softasept N, B Braun, Melsungen, Germany). Sterile covers (Cardinal Health, Voisins le Bretonneux, France) were applied to the surgical field. After a longitudinal midline incision, one of the two uterine horns was ligated at the utero-tubal junction and utero-cervical junction. Haemostasis after resection of the uterine horn was performed by bipolar coagulation. The endometrium was exposed by longitudinal incision and the horn was divided into four pieces, each measuring $6 \mathrm{~mm} \mathrm{x}$ $3 \mathrm{~mm}$. Two pieces of the uterine horn were sewed on each sidewall of the peritoneum respectively, with the endometrium facing the peritoneal cavity. Implants were documented with calibrated photos (Canon EOS 350D, Canon Inc., Tokyo, Japan).

The midline laparotomy was closed in two layers. The musculoperitoneal layer was closed with a running suture (Vicryl 3-0, Ethicon, Norderstedt, Germany) and the skin was closed with clips (Leukoclip SD, Smith \& Nephew GmbH Wound Management, Schenefeld, Germany). After surgery the animals received analgesia with buprenorphine (0.05 $\mathrm{mg} / \mathrm{kg}$ ) subcutaneously every 6 hours until post-operative day 2.

All operations were performed by the same surgeons (C.T., C.P., B.K.).

\section{Second surgery: treatment of endometriosis}

Second surgery for endometriosis treatment was performed 14 days after endometriosis induction according to the aforementioned methodologies for anesthesia, abdominal incision and laparotomy closure. All implants were photodocumented before treat- 
ment. According to randomization, both endometriotic foci on one side of the peritoneum were surgically removed using a standard scalpel (blade no. 11, B.Braun, Melsungen AG, Germany) Bleedings were stopped with a bipolar coagulation clamp and the resected tissue was evaluated histologically to ascertain the success rate of endometriosis induction. Both endometrial grafts on the opposite sidewall of the peritoneum were ablated with aerosol plasma coagulation. For each endometriosis site the time needed for ablation or resection including hemostasis was measured and recorded. Lesions were photo documented after treatment. All treatments were performed by the same surgeons (C.T., C.P.).

\section{Technical devices, parameters, and agents}

The modular VIO generator (VIO 300D; Erbe Elektromedizin $\mathrm{GmbH}$, Tuebingen, Germany) was used as the radiofrequency system.

For AePC, an aerosol plasma applicator as described earlier (4) was used. This hybrid instrument combines the standard APC with a very fine spray of sterile saline. The AePC setting was PULSED APC effect 1 with a maximal power of $25 \mathrm{~W}$. The argon flow was set to $0.4 \mathrm{l} / \mathrm{min}$. The tip of the APC probe was kept at a distance of 2 to $3 \mathrm{~mm}$ from the peritoneal tissue in all cases. The number of radiofrequency impulses varied between the different lesions and was based on the experience of the surgeon to macroscopically remove the lesions. A storage oscilloscope (LeCroy W6050A, $500 \mathrm{MHz}$, LeCroy Corp., New York, USA) was used to measure the basic parameters voltage (U), current (I) and application time (t), from which the energy intake (E) by AePC can be calculated for each lesion by $E=P^{*} t=U^{*} I^{*} t$, where $(P)$ stands for the electrical power.

Calibrated photos from endometriosis sites at different stages (after transplantation, before and after treatment) were evaluated with use of the software AxioVision LE Rel. 4.4 (Carl Zeiss MicroImaging $\mathrm{GmbH}$, Jena, Germany).

\section{Third surgery: evaluation of therapy success}

14 days after treatment the rats were euthanized with carbon dioxide for the evaluation of the therapeutical success. The trauma sites were photo documented. Finally the peritoneal trauma sites were excised, fixed in $4.5 \%$ phosphate buffered formalin, embedded in paraffin and cut into $3 \mu \mathrm{m}$ sections. The slides were then stained with haematoxylin and eosin and observed under a light microscope (Carl Zeiss MicroImaging $\mathrm{GmbH}$, Jena, Germany) by the same pathologist (M.S.). Calibrated photographs were taken using a Zeiss Axio Scope microscope in combination with a AxioCam MRc camera and the ZEN 2012 software, Version 6.39 (Carl ZEISS, Germany). In order to ascertain the eradication rate, endometrial epithelium was assessed for its presence or absence and categorized into five groups based on the score by Keenan et al. [5] plus one additional category: absence of endometrial lining (0), poorly preserved/very rarely preserved endometrial lining (1), moderately preserved endometrial lining and leucocyte infiltration (2), well preserved endometrial lining/ epithelial layer (3) and fairly moderate endometrial lining (with nuclei still present). The latter and added category is placed between 1 and 2 of the Keenan score and was introduced because some of the observed endometrial epithelia were unsuitable for the given categories. It describes moderately preserved endometrial lining which is starting to fade away.

The degree of inflammation (acute and/or chronic) and the degree of myonecrosis was classified into the following groups: none, low, moderate or high. Carbonization with or without foreign body reactions were also examined and evaluated.

The pathologist (M.S.) was blinded to the different therapy methods.

\section{Statistics}

Data was collected and analysed by means of descriptive statistics (mean and standard deviation), as well as by statistical hypothesis testing. For non-inferiority of AePC and SR in eradication rate of endometriosis, the McNemar test for pair-by-pair comparison of opposing lesions was used to take a positive correlation coefficient between the two sidewalls into consideration. A lesion pair was defined as one implant treated with AePC and one implant from the opposite sidewall which was removed using a scalpel. Comparisons between groups were performed by Fisher's exact test for categorical variables (foreign bodies, carbonization). The Mann Whitney test was used for non-normally distributed variables (intervention time, scores for chronic and acute inflammation, scores for myonecrosis, growth of endometrial implants). The t-test was used for normally distributed variables (size of endometrial implants), the t-test with Welch correction was used for normally distributed variables with different variances (size of coagulation area). All $p$ values ( $p<0.05$ was considered statistically significant) were two-sided and were not adjusted for the number of parameters evaluated. Statistical analysis was accomplished using the statistic software PRISM 5.04 (Graphpad Software, Inc, La Jolla, USA).

For estimation of the sample size, a level of significance of $5 \%$ and a power of $90 \%$ were used to reveal statistical significance for the difference of success probabilities of $90 \%$ and $65 \%$. The correlation 
coefficient between neighbouring lesions was assumed to be 0 .

In each animal the side of the peritoneum for the AePC group was randomized using a computer-generated random number procedure, whereas the opposite side was used for the SR group.

\section{Results}

34 rats were used to perform 132 endometriosis transplantations and a total of $64 \mathrm{AePC}$ applications and 64 surgical resections. One rat died before the first surgery due to anaesthesia problems. One rat had to be euthanized after the first surgery and one rat was sacrificed after the second operation due to severe infection as a consequence of auto-cannibalism. 31 rats tolerated the standardized procedures well. All laparotomy sites were intact. A flow chart with the number of animals and resulting lesion pairs is summarized in figure 1 .

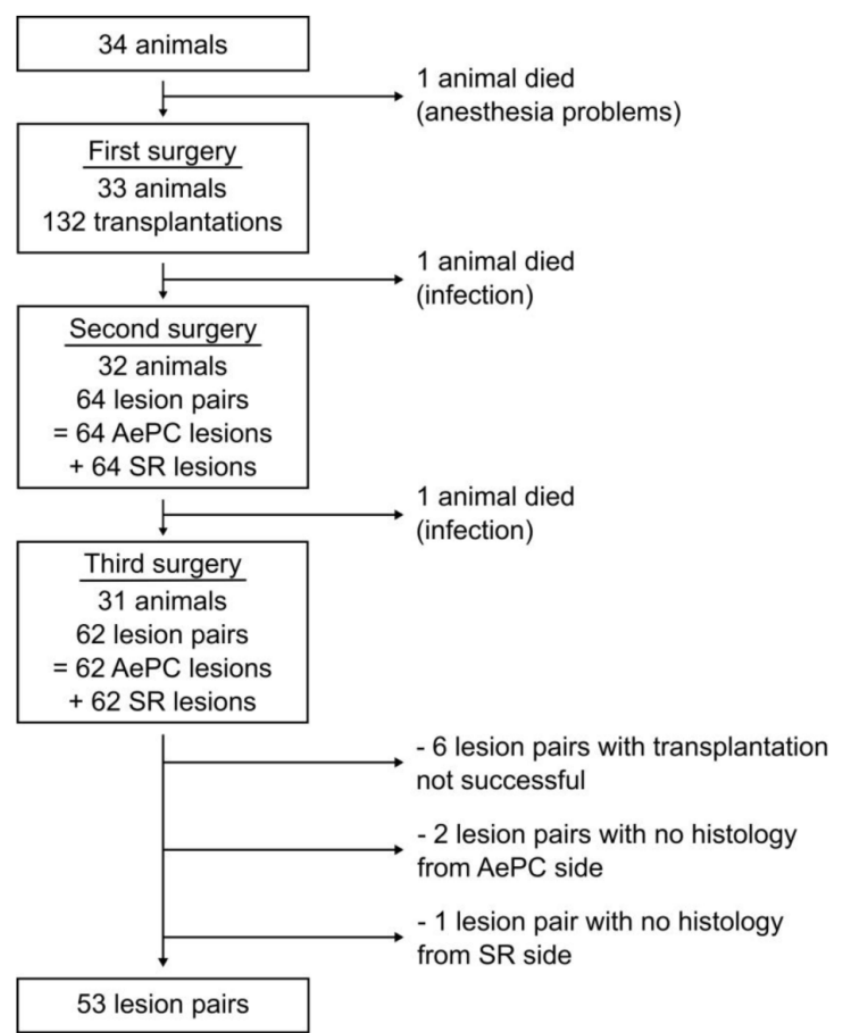

Figure 1: Flow chart with the number of animals and resulting lesion pairs.

\section{Success of endometriosis induction}

The size of endometriosis implants directly after transplantation was $28.6 \pm 9.3 \mathrm{~mm}^{2}$. 14 days later, implants showed a significant increase in size to $48.3 \pm$ $19.8 \mathrm{~mm}^{2}(\mathrm{p}<0.0001)$. Implants on the AePC side and SR side were comparable $(p=0.28)$. Most of the vesicular endometrial cysts were fluid-filled and vascular- ized. Figure 2 depicts implants immediately (Fig. 2A) and 14 days after transplantation (Fig. 2B).

The rate of successful endometriosis induction was histologically proven after resection of the grafts. Transplantation was successful in 90.1\% (58/64). All 6 cases without endometriosis were excluded from further evaluation.

\section{Energy intake, number of AePC impulses and area of coagulation}

An average energy intake of $616 \pm 245 \mathrm{~J}$ by $24.1 \pm$ 9.7 impulses was applied for ablation of endometriosis sites with aerosol plasma coagulation. The macroscopic area of coagulation was $50.0 \pm 12.7 \mathrm{~mm}^{2}$ for AePC and $44.6 \pm 23.5 \mathrm{~mm}^{2}$ for $\mathrm{SR}(\mathrm{p}=0.16)$. Figure 3 displays the macroscopic tissue effect after AePC (Fig. 3A) and SR (Fig. 3B).

\section{Duration of intervention}

The surgical resection including haemostasis was $51.8 \pm 16.5 \mathrm{~s}$ per lesion. Interventions with AePC were significantly faster with $22.1 \pm 9.7 \mathrm{~s}(\mathrm{p}<0.0001)$.

\section{Evaluation of endometriosis therapy}

The eradication rate after endometriosis treatment was histologically determined 14 days after intervention. From 34 animals, $60 \mathrm{AePC}$ and 61 SR single lesions could be achieved for histologic evaluation resulting in a total number of 53 lesion pairs (one implant treated with $\mathrm{AePC}$, the implant on the opposite side removed using a scalpel). In $88.7 \%(47 / 53)$ of lesion pairs, endometriosis was successfully removed from both the SR and their corresponding AePC treated sides. $1.9 \%(1 / 53)$ of the lesion pairs showed remnants of endometrial implants on the resection side only and in $9.4 \%(5 / 53)$ of lesion pairs remains of endometriosis were detected on the AePC treated side only. There were no pairs $(0 / 53)$ with endometrial residues on both sidewalls of one pair of lesions. The McNemar test for direct comparison of pairs revealed both methods to be statistically not significantly different $(p=0.22)$. Figure 4 depicts residual endometrial implants which remained after incomplete resection. Table 1 summarizes the results. The histologic grading of the endometrial implants is shown in Table 2.

Table 1: Pairwise comparison of eradication by AePC or SR $(p=0.22)$.

\begin{tabular}{lll}
\hline AePC & SR & Frequency \\
\hline $\begin{array}{l}\text { no endometriosis } \\
\text { no endometriosis }\end{array}$ & $\begin{array}{l}\text { no endometriosis } \\
\text { remnants of endometrial im- } \\
\text { plants }\end{array}$ & $\begin{array}{l}47 / 53(88.7 \%) \\
1 / 53(1.9 \%)\end{array}$ \\
$\begin{array}{l}\text { nomnants of endometrial } \\
\text { implants }\end{array}$ & $5 / 53(9.4 \%)$ \\
$\begin{array}{l}\text { remnants of endometrial } \\
\text { implants }\end{array}$ & $\begin{array}{l}\text { remnants of endometrial im- } \\
\text { plants }\end{array}$ & $0 / 53(0 \%)$
\end{tabular}


Table 2: Histologic grading of endometrial lining 14 days after treatment.

\begin{tabular}{llllll}
\hline & $\begin{array}{l}\text { Absence of } \\
\text { endometrial } \\
\text { lining }\end{array}$ & $\begin{array}{l}\text { Poorly pre- } \\
\text { served en- } \\
\text { dometrial } \\
\text { lining }\end{array}$ & $\begin{array}{l}\text { Fading } \\
\text { endometrial } \\
\text { lining }\end{array}$ & $\begin{array}{l}\text { Moderately } \\
\text { preserved } \\
\text { endometrial } \\
\text { lining }\end{array}$ & $\begin{array}{l}\text { Well pre- } \\
\text { served } \\
\text { endometrial } \\
\text { lining }\end{array}$ \\
\hline AePC & $55(91.7 \%)$ & $0(0 \%)$ & $4(6.6 \%)$ & $1(1.7 \%)$ & $0(0 \%)$ \\
SR & $60(98.4 \%)$ & $1(1.6 \%)$ & $0(0 \%)$ & $0(0 \%)$ & $0(0 \%)$ \\
\hline
\end{tabular}

\section{Further histologic results}

The histological evaluation revealed an overall moderate chronic inflammation for the SR samples and an overall moderate to high chronic inflammation for the AePC treated lesions 14 days after AePC and SR intervention. Figure 5 depicts histological findings of AePC treated lesions (Fig. 5A) and lesions created by SR (Fig. 5FB). Compared to the SR group, the AePC treated sites showed more cases graded as high for acute inflammation and myonecrosis $(p<0.0001)$. Carbonization with foreign body reaction was found in $63.3 \%$ of AePC treated lesions and in $18.0 \%$ of SR sites as radiofrequency was only applied for coagulation purposes $(\mathrm{p}<0.0001)$.

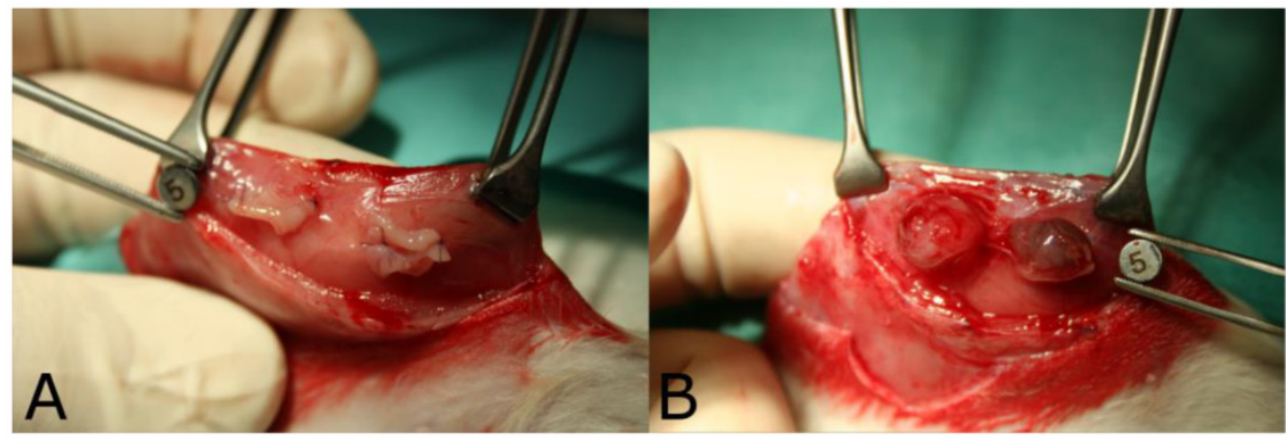

Figure 2: Endometriosis implants A) immediately and B) 14 days after transplantation.

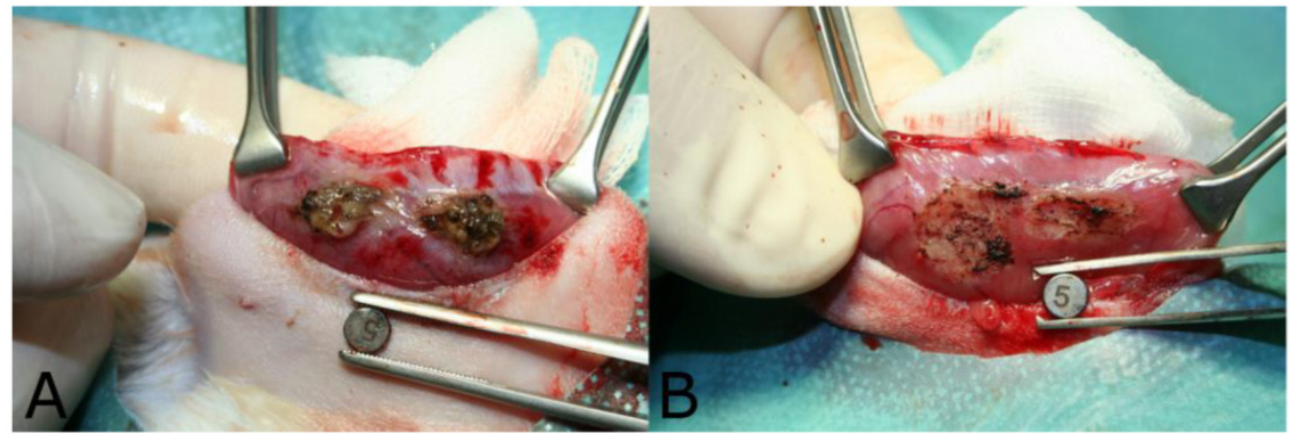

Figure 3: Macroscopic tissue effect after A) aerosol plasma coagulation and B) surgical resection.

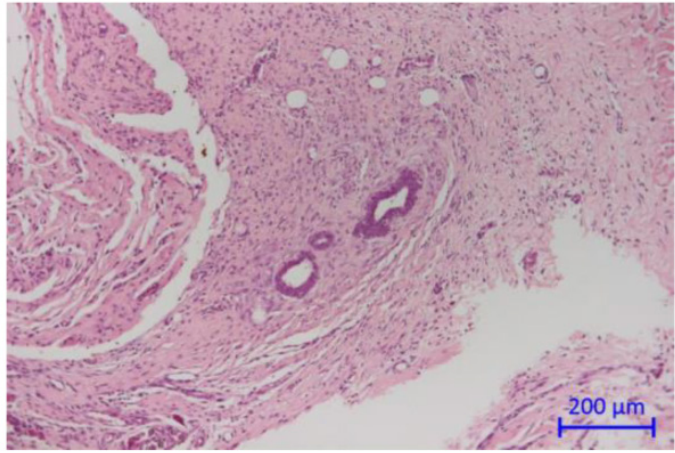

Figure 4: Cross section of the abdominal wall showing connective tissue with infiltrating endometrial glands.

\section{Discussion}

Therapy for endometriosis must be thoroughly planned according to the patient's individual symptoms and needs with pain and sterility being the main issues. At present, the complete resection of deep infiltrating endometriosis is the therapy of choice [6] with a positive effect on pain, quality of life and fertility [7]. Clinically, it could be demonstrated that the success rates of spontaneous conception and assisted reproductive methods increase after the removal of deep infiltrating and peritoneal endometriosis [8,9]. To date, the latter can usually be achieved by minimally invasive laparoscopic techniques with various instruments such as "cold" scissors as well as energy-based devices of which APC is a valuable option. 
In a clinical setting argon plasma was efficacious and safe for the complete resection of endometriotic implants [10]; however the close combination of the least possible adhesion formation and lateral tissue damage induced by thermal effects and the complete therapy by total resection of affected areas remains the major challenge for all heat induced surgical techniques.

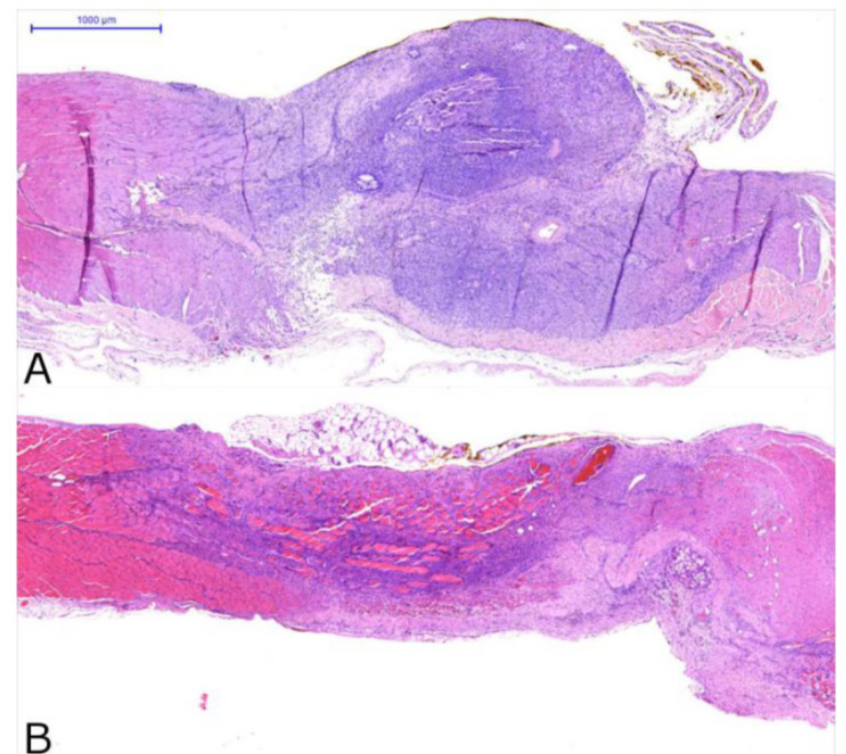

Figure 5: Cross sections of the abdominal wall 14 days after AePC (A) and surgical resection $(B)$. Both figures demonstrate an overall moderate degree of inflammation with granulation tissue formation and myonecrosis.

Therefore, superiority of one approach has not yet been defined and this study compares the eradication rate of sharp resection versus AePC in a rodent model where remaining endometrial tissue after treatment can be diagnosed histopathologically.

The design of endometriosis models is difficult as reliable and comparable foci of interest with endometrial tissue are needed that are suitable for consecutive therapy. Our animal model is based upon previously published literature describing the auto-transplantation of endometrium with consecutive laparotomies [11-16]. All rats were given estradiol one day before endometriosis induction for hormonal synchronization. Since primary endometriosis and recurrence are estrogen-dependent [17-19] it is unclear whether oophorectomy should be performed in order to inhibit fluctuation of estrogen levels and to ensure that experimental endometriotic implants present the same activity on the peritoneal surface. According to previous experiments [16] and to minimize the surgical trauma, we preserved the ovaries and observed a significant growth of the transplanted lesions $(p<0.0001)$ that were of comparable size and macroscopic aspect in both groups (AePC vs. SR, $\mathrm{p}=0.28$ ). Unmodified physiological ovarian estrogen activity after the resection or coagulation of endometriosis in both groups (second look) also allows for potential recurrence in the treated areas investigated in the third operation (third look). At present, complete resection or destruction is the therapy of choice if endometriosis is managed surgically $[6,20]$. Resection can be achieved easily in open surgery and in areas where adjacent structures such as bowel, bladder or ureter are unlikely to be injured; however this is not always the case in laparoscopy or if the aforementioned organs are affected directly or with the risk of (thermal) lateral damage. We are aware of the methodological problem that the assessment of complete resection (SR group) and destruction (AePC group) of endometriotic lesions is difficult to compare and ultimately dependent on the surgeon's skills and experience regarding the anticipated depth of the lesion. We therefore tried to reduce bias by the pairwise comparison of the eradication sites as presented in table $1.1 .9 \%$ of the lesion pairs showed remnants of endometrial epithelium on the resection side only and in $9.4 \%$ of lesion pairs, remainders of endometriosis were detected on the AePC treated side only. This was not statistically significant $(p=0.22)$ indicating that AePC and related techniques are not inferior with respect to the eradication of endometriosis in the presented model. We speculate that standard APC is expected to achieve comparable eradication rates with AePC; however the side effects such as adhesion formation are greater as previously demonstrated [4].

With respect to operation time we could investigate that AePC was significantly faster in comparison to SR $(p<0.0001)$. This could be hypothesized as sharp resection of endometriosis on the peritoneal surface requires a meticulous preparation technique in order to completely remove the area of interest and to reduce unwanted trauma with subsequent adhesion formation. Furthermore, the change of instruments and haemostasis of the resection area with a bipolar coagulation clamp required additional time. In contrast, AePC can be directly applied from a defined distance, which was $2-3 \mathrm{~mm}$ in this setting, to allow for complete treatment without changing the instrument for further haemostasis. We are aware of the limitation in this study that both cold resection and AePC may vary between the lesions, since the SR and the number of radiofrequency pulses (AePC) are based on the surgeon's evaluation to macroscopically remove the lesions upon second look. Clinically, laparoscopy demonstrates various benefits for endometriosis patients [21-25] and health care systems due to shorter operation and recovery times [26]. It has to be taken into account that AePC was applied in an open fashion in this animal setting, however argon plasma 
can easily be used laparoscopically [10] with the potential to further reduce total operation time.

The animal model used in this study is not suitable to investigate adhesiogenesis as the formation of adhesions is already triggered by a local inflammatory response inflicted on the peritoneal site after transplantation of endometriotic foci to the rat's peritoneum. Adhesions induced by the intervention itself would not be distinguishable from adhesions induced by transplantation in the endometriosis rat model. However, we have already demonstrated in a different rat model specifically for adhesiogenesis that argon plasma itself can induce adhesion formation [27] and consequently we could observe that the improvement of the peritoneal conditions with an aerosol in combination with APC seems to have a significant positive effect against adhesions [4].

AePC sites showed higher degrees of acute inflammation, myonecrosis and carbonization with foreign body reaction $(\mathrm{p}<0.0001)$. This can be explained by the fact that in the SR group the thermal effect of radiofrequency coagulation was only applied to achieve haemostasis of minor bleeding of the resection area. According to Bhatta et al. [28] the histological depth of thermal lesions did not correlate with the formation of adhesions in contrast to carbonization and charring. The onset of the inflammatory adhesion cascade by thermal effects and local peritoneal conditions is under investigation [29-32]. In this context, it has to be stated that endometriosis is related to oxidative stress [33], the immunoexpression of heat shock proteins [34] and other various inflammatory reactions [18,35]. As the focus of this animal study is on the complete destruction of endometriosis with SR versus AePC representing a non-direct mode of eradication, we consider the fact that AePC is not inferior as clinically more relevant than the histological observation of an expected acute inflammation.

Regarding the possible eradication rate of deep infiltrating endometriosis, we assume that the water jet technology inflicted onto the lesion with AePC might be able to create a water cushion between the affected tissue and the adjacent organs thus better separating the healthy area from the spots to be treated. This will have to be investigated in further experiments even though it is difficult to create models that represent deep infiltrating endometriosis in the same fashion as can be clinically found in human patients.

Hybrid technologies, such as the combination of waterjet with radiofrequency ablation (e.g. APC), are easily accessible on the market and successfully applied in other medical fields; however at present, APC does not play a major role in gynecology, with only a few centers already using plasma energy for the treatment of endometriosis. We could clearly demonstrate in our previous studies that non-contact argon plasma coagulation, especially when combining APC with an aerosol of liquid and gas, is significantly less associated with adhesion side-effects compared to other coagulation methods [4] with is very likely to fully compensate for the additional cost of a generator and single use probes.

\section{Conclusion}

With respect to the complete eradication of auto-transplanted endometriotic lesions, non-contact AePC is not inferior compared to standard sharp resection (SR). The AePC treatment is significantly faster. In some AePC cases a higher degree of inflammatory reaction could be observed histologically, which warrants further investigations to improve thermal side effects and peritoneal conditions of this method that can serve as an alternative to SR in the clinical setting of endometriosis.

\section{Acknowledgment}

The authors thank M. Eichner, M.D., Department of Medical Biometry, University of Tuebingen, Tuebingen, Germany, for his assistance in the statistical evaluation of the number of animals used in this study.

\section{Funding}

This study was supported by Erbe Elektromedizin $\mathrm{GmbH}$.

\section{Ethical approval}

This animal study was approved by the Institutional Review Board (Ethics Committee of the Regional Board in Tuebingen, Germany, registration number F 1-13).

\section{Authors' contributions}

Study conception and design: Ralf Rothmund, Markus Dominik Enderle, Alexander Neugebauer, Kristin Kroeker, Falko Fend, Sara Brucker, and Bernhard Kraemer.

Acquisition of data: Marcus Scharpf, Christos Tsaousidis, Constanze Planck, Alexander Neugebauer, Kristin Kroeker, and Daniela Nuessle.

Analysis and interpretation of data: Ralf Rothmund, Marcus Scharpf, Christos Tsaousidis, Constanze Planck, Markus Dominik Enderle, Alexander Neugebauer, Kristin Kroeker, Daniela Nuessle, and Bernhard Kraemer.

Drafting of manuscript: Marcus Scharpf, Christos Tsaousidis, Constanze Planck, Alexander Neugebauer, Kristin Kroeker, Daniela Nuessle, and Bernhard Kraemer. 
Critical revision of manuscript: Ralf Rothmund, Marcus Scharpf, Christos Tsaousidis, Constanze Planck, Markus Dominik Enderle, Alexander Neugebauer, Kristin Kroeker, Daniela Nuessle, Falko Fend, Sara Brucker, and Bernhard Kraemer.

\section{Competing interests}

The authors RR, MS, CT, CP, FF, SB and BK have no conflicts of interest to disclose in relation to the submitted manuscript. The authors MDE, AN, KK and DN are employees of Erbe research department, Germany.

\section{References}

1. Macer ML, Taylor HS. Endometriosis and infertility: a review of the pathogenesis and treatment of endometriosis-associated infertility. Obstet Gynecol Clin North Am. 2012; 39: 535-549.

2. Garry R. The effectiveness of laparoscopic excision of endometriosis. Curr Opin Obstet Gynecol. 2004; 16(4): 299-303.

3. Roman $\mathrm{H}$, Auber M, Bourdel N, et al. Postoperative recurrence and fertility after endometrioma ablation using plasma energy: retrospective assessment of a 3-year experience. J Minim Invasive Gynecol. 2013; 20(5): 573-582.

4. Kraemer B, Rothmund R, Fischer K, et al. A prospective randomized experimental study to investigate the peritoneal adhesion formation of argon plasma coagulation (APC) versus a novel aerosol plasma in a rat model. Surg Innov. 2013; 21(4): 389-397.

5. Keenan JA, Williams-Boyce PK, Massey PJ, et al. Regression of endometrial explants in a rat model of endometriosis treated with the immune modulators loxoribine and levamisole. Fertil Steril. 1999; 72(1): 135-141.

6. Meuleman C, Tomassetti C, D'Hooghe TM. Clinical outcome after laparoscopic radical excision of endometriosis and laparoscopic segmental bowel resection. Curr Opin Obstet Gynecol. 2012; 24: 245-252.

7. Bassi MA, Podgaec S, Dias JA Jr, et al. Quality of life after segmental resection of the rectosigmoid by laparoscopy in patients with deep infiltrating endometriosis with bowel involvement. J Minim Invasive Gynecol. 2011; 18: 730-733.

8. Hart RJ, Hickey M, Maouris $P$, et al. Excisional surgery versus ablative surgery for ovarian endometriomata. Cochrane Database Syst Rev. 2008; DOI:10.1002/14651858.CD004992.pub2.

9. Bianchi PH, Pereira RM, Zanatta A, et al. Extensive excision of deep infiltrative endometriosis before in vitro fertilization significantly improves pregnancy rates. J Minim Invasive Gynecol. 2009; 16: 174-180.

10. Nezhat C, Kho KA, Morozov V. Use of Neutral Argon Plasma in the Laparoscopic Treatment of Endometriosis. J Soc Laparoend. 2009; 13: 479-483.

11. Hascalik S, Celik O, Kekilli E, et al. Novel noninvasive detection method for endometriosis: research and development of scintigraphic survey on endometrial implants in rats. Fertil Steril. 2008; 90(1): 209-213.

12. Güney M, Oral B, Karahan N, et al. Regression of endometrial explants in a rat model of endometriosis treated with melatonin. Fertil Steril. 2009; 89(4): 934-942.

13. Yavuz E, Oktem M, Esinler I, et al. Genistein causes regression of endometriotic implants in the rat model. Fertil Steril. 2007; 88 (Suppl 4): 1129-1134.

14. Akkaya P, Onalan G, Haberal N, et al. Doxycycline causes regression of endometriotic implants: a rat model. Hum Reprod. 2009; 24(8): 1900-1908.

15. Vernon MW, Wilson EA. Studies on the surgical induction of endometriosis in the rat. Fertil Steril. 1985; 44(5): 684-694.

16. Yildirim G, Attar R, Ficicioglu C, et al. Etanercept causes regression of endometriotic implants in a rat model. Arch Gynecol Obstet. 2011; 283(6): 1297-1302.

17. Vercellini P, Viganò P, Somigliana E, et al. Endometriosis: pathogenesis and treatment. Nat Rev Endocrinol. 2014; 10(5): 261-275.

18. Colette S, Donnez J. Are aromatase inhibitors effective in endometriosis treatment? Expert Opin Investig Drugs. 2011; 20(7): 917-931.

19. Becker CM, D'Amato RJ. Angiogenesis and antiangiogenic therapy in endometriosis. Microvasc Res. 2007; 74(2-3): 121-130.

20. Koninckx PR, Ussia A, Adamyan L, et al. Deep endometriosis: definition, diagnosis, and treatment. Fertil Steril. 2012; 98(3): 564-571.

21. Deguara CS, Pepas L, Davis C. Does minimally invasive surgery for endometriosis improve pelvic symptoms and quality of life? Curr Opin Obstet Gynecol. 2012; 24(4): 241-244.

22. Touboul C, Ballester M, Dubernard G, et al. Long-term symptoms, quality of life, and fertility after colorectal resection for endometriosis: extended analysis of a randomized controlled trial comparing laparoscopically assisted to open surgery. Surg Endosc. 2015; 29(7): 1879-1887

23. Zanatta A, Rosin MM, Machado RL, et al. Laparoscopic Dissection and Anatomy of Sacral Nerve Roots and Pelvic Splanchnic Nerves. J Minim Invasive Gynecol. 2014; 21(6): 982-983.
24. Walch K, Kernstock T, Poschalko-Hammerle G, et al. Prevalence and severity of cyclic leg pain in women with endometriosis and in controls - effect of laparoscopic surgery. Eur J Obstet Gynecol Reprod Biol. 2014; 179: 51-57.

25. Collinet $P$, Leguevaque $P$, Neme RM, et al. Robot-assisted laparoscopy for deep infiltrating endometriosis: international multicentric retrospective study. Surg Endosc. 2014; 28(8): 2474-2479.

26. Lassen PD, Moeller-Larsen H, DE Nully P. Same-day discharge after laparoscopic hysterectomy. Acta Obstet Gynecol Scand. 2012; 91(11): 1339-1341.

27. Kraemer B, Rothmund R, Fischer K, et al. A prospective, randomized, experimental study to investigate the peritoneal adhesion formation of noncontact argon plasma coagulation in a rat model. Fertil Steril. 2011; 95(4): 1328-1332.

28. Bhatta N, Isaacson K, Flotte T, et al. Injury and adhesion formation following ovarian wedge resection with different thermal surgical modalities. Lasers Surg Med. 1993; 13(3): 344-352.

29. Kraemer B, Scharpf M, Planck C, et al. Randomized experimental study to investigate the peritoneal adhesion formation of conventional monopolar contact coagulation versus noncontact argon plasma coagulation in a rat model. Fertil Steril. 2014; 102(4): 1197-1202.

30. Binda MM, Koninckx PR. Prevention of adhesion formation in a laparoscopic mouse model should combine local treatment with peritoneal cavity conditioning. Hum Reprod. 2009; 24(6): 1473-1479.

31. Corona R, Binda MM, Mailova K, et al. Addition of nitrous oxide to the carbon dioxide pneumoperitoneum strongly decreases adhesion formation and the dose-dependent adhesiogenic effect of blood in a laparoscopic mouse model. Fertil Steril. 2013; 100(6): 1777-1783.

32. Koninckx PR, Corona R, Timmerman D, et al. Peritoneal full-conditioning reduces postoperative adhesions and pain: a randomised controlled trial in deep endometriosis surgery. J Ovarian Res. 2013; 6(1): 90.

33. Rosa e Silva JC, do Amara VF, Mendonça JL, et al. Serum markers of oxidative stress and endometriosis. Clin Exp Obstet Gynecol. 2014; 41(4): 371-374.

34. Imamura T, Khan KN, Fujishita A, et al. Effect of GnRH agonist therapy on the expression of human heat shock protein 70 in eutopic and ectopic endometria of women with endometriosis. Eur J Obstet Gynecol Reprod Biol. 2014; 180: $16-23$

35. Greaves E, Cousins FL, Murray A, et al. A novel mouse model of endometriosis mimics human phenotype and reveals insights into the inflammatory contribution of shed endometrium. Am J Pathol. 2014; 184(7): 1930-1939. 